\title{
The PhoBR two-component system regulates antibiotic biosynthesis in Serratia in response to phosphate
} Tamzin Gristwood ${ }^{1,2}$, Peter C Fineran ${ }^{1,2}$, Lee Everson ${ }^{1}$, Neil R Williamson ${ }^{1}$ and George P Salmond*1

\author{
Address: ${ }^{1}$ Department of Biochemistry, University of Cambridge, Cambridge, CB2 1QW, UK and ${ }^{2}$ Current address: Department of Microbiology \\ \& Immunology, University of Otago, PO Box 56, Dunedin, New Zealand \\ Email: Tamzin Gristwood - tamzin.gristwood@otago.ac.nz; Peter C Fineran - peter.fineran@otago.ac.nz; \\ Lee Everson - le212@mole.bio.cam.ac.uk; Neil R Williamson -nrw26@mole.bio.cam.ac.uk; George P Salmond* - gpcs@mole.bio.cam.ac.uk \\ * Corresponding author
}

Published: 28 May 2009

BMC Microbiology 2009, 9:1/2 doi:10.1186/147/-2180-9-1/2
Received: II December 2008

Accepted: 28 May 2009

This article is available from: http://www.biomedcentral.com/I47I-2/80/9/II2

(c) 2009 Gristwood et al; licensee BioMed Central Ltd.

This is an Open Access article distributed under the terms of the Creative Commons Attribution License (http://creativecommons.org/licenses/by/2.0), which permits unrestricted use, distribution, and reproduction in any medium, provided the original work is properly cited.

\begin{abstract}
Background: Secondary metabolism in Serratia sp. ATCC 39006 (Serratia 39006) is controlled via a complex network of regulators, including a LuxIR-type (SmalR) quorum sensing (QS) system. Here we investigate the molecular mechanism by which phosphate limitation controls biosynthesis of two antibiotic secondary metabolites, prodigiosin and carbapenem, in Serratia 39006.

Results: We demonstrate that a mutation in the high affinity phosphate transporter pstSCAB-phoU, believed to mimic low phosphate conditions, causes upregulation of secondary metabolism and QS in Serratia 39006, via the PhoBR two-component system. Phosphate limitation also activated secondary metabolism and QS in Serratia 39006. In addition, a pstS mutation resulted in upregulation of rap. Rap, a putative SlyA/MarR-family transcriptional regulator, shares similarity with the global regulator RovA (regulator of virulence) from Yersina spp. and is an activator of secondary metabolism in Serratia 39006. We demonstrate that expression of rap, pigA-O (encoding the prodigiosin biosynthetic operon) and smal are controlled via PhoBR in Serratia 39006.
\end{abstract}

Conclusion: Phosphate limitation regulates secondary metabolism in Serratia 39006 via multiple inter-linked pathways, incorporating transcriptional control mediated by three important global regulators, PhoB, SmaR and Rap.

\section{Background}

Phosphate is an essential component of numerous biomolecules. Therefore, the control of intracellular phosphate concentrations is vital for bacterial survival. At least two major systems are involved in managing intracellular concentrations of inorganic orthophosphate $\left(\mathrm{P}_{\mathrm{i}}\right)$, the preferred primary source of phosphate [1]. When $P_{i}$ is abundant, the low affinity Pit transporter appears to be primarily responsible for $P_{i}$ uptake [2-4]. When $P_{i}$ becomes limited, the high affinity Pst transport system (PstSCAB-PhoU) is activated, and takes over as the predominant $P_{\mathrm{i}}$ uptake system [5-8].

In Escherichia coli and other Enterobacteriaceae, the cellular response to $P_{i}$ availability is mediated via the PhoBR two-component system. Under conditions of $\mathrm{P}_{\mathrm{i}}$ limitation, the sensor histidine kinase PhoR is autophosphorylated [9]. PhoR then activates its cognate response 
regulator, PhoB [9], which in turn activates expression of multiple genes, termed the Pho regulon, via direct binding to a conserved Pho box sequence found overlapping 35 regions in target gene promoters [10-12]. In E. coli, the Pho regulon is believed to consist of approximately 30 genes involved in the adaptation to survival under low $P_{i}$ conditions, including pstSCAB-phoU and phoBR [1]. Phosphate regulation is controlled via similar mechanisms in Bacillus subtilis and Streptomyces species, although the consensus Pho boxes are different in each system $[13,14]$. Mutations in the pstSCAB-phoU operon result in constitutive activation of PhoR and hence, constitutive phosphorylation of PhoB $[15,16]$. Therefore, pst mutants are proposed to mimic low $\mathrm{P}_{\mathrm{i}}$ conditions.

$P_{i}$ has been found to negatively regulate the biosynthesis of antibiotics and other secondary metabolites in multiple bacterial species (reviewed in [17]). However, the complex molecular mechanisms underlying the $\mathrm{P}_{\mathrm{i}}$ mediated regulation of secondary metabolism are not well characterised. In this study we investigate the role of the PhoBR two-component system, and $\mathrm{P}_{\mathrm{i}}$ availability, on the regulation of antibiotic production in the Gram-negative Enterobacteriaceae, Serratia sp. ATCC 39006 (Serratia 39006). Serratia 39006 synthesises the red, tripyrrole antibiotic, prodigiosin (Pig; 2-methyl-3-pentyl-6-methoxyprodigiosin) [18]. The natural physiological role of Pig in the producing organism may be as an antimicrobial agent [19]. In addition, Pig is of clinical interest due to the observed anticancer and immunosuppressive properties of this compound [20-22]. Serratia 39006 also produces the $\beta$-lactam antibiotic, carbapenem (Car; 1-carbapen-2em-3-carboxylic acid) $[23,24]$. Both the Pig and Car biosynthetic gene clusters have been characterised ( $p i g A-O$ and carA- $H$, respectively) $[25,26]$.

Production of secondary metabolites in Serratia 39006 is controlled by a hierarchial network of regulators [27]. This includes a LuxIR-type quorum sensing (QS) system (SmaIR) $[25,28,29]$, which allows gene expression to be regulated in response to cell density via the production and detection of low molecular weight signal molecules [30]. In Serratia 39006, the N-acyl homoserine lactone (AHL) synthase SmaI produces two signalling molecules, $\mathrm{N}$-butanoyl-L-homoserine lactone (BHL) and $\mathrm{N}$-hexanoyl-L-homoserine lactone (HHL), with BHL being the major product [25]. At low cell density, SmaR acts as a transcriptional repressor of target genes $[28,29]$. At high cell density, and hence high BHL/HHL levels, SmaR binds $\mathrm{BHL} / \mathrm{HHL}$, resulting in decreased DNA-binding affinity with a consequent alleviation of repression. QS controls secondary metabolism in Serratia 39006 via at least four other regulatory genes (carR, pigQ, pigR and rap) $[28,29]$. The putative SlyA/MarR-family transcriptional regulator, Rap (regulator of antibiotic and pigment), is an activator of Pig and Car production in Serratia 39006 [31]. Rap shares similarity with the global transcriptional regulator RovA (regulator of virulence) from Yersina spp. [32-34]. More than 20 additional genes have been shown to regulate secondary metabolism in Serratia 39006, and these are predicted to be responding to additional environmental stimuli $[19,27,35,36]$.

Previously, we demonstrated that, in Serratia 39006, mutations within genes predicted to encode homologues of the E. coli PstSCAB-PhoU phosphate transport system resulted in over-production of both Pig (10-fold) and Car (2-fold), at the level of transcription of the biosynthetic genes [29]. In this study we investigate further the molecular mechanism by which these effects are occurring. We demonstrate that secondary metabolism in Serratia 39006 is upregulated in response to mutations in PstSCAB-PhoU or $\mathrm{P}_{\mathrm{i}}$ limitation, via the PhoBR two-component system. In addition, we provide evidence that expression of the smal, pigA and rap genes are activated via PhoBR in Serratia 39006. Hence, we propose a model in which $P_{\mathrm{i}}$ limitation increases secondary metabolism in Serratia 39006 via multiple, inter-linked pathways, incorporating the global transcriptional regulators $\mathrm{PhoB}, \mathrm{SmaR}$ and Rap.

\section{Results \\ Sequence analysis of the pstSCAB-phoU operon in Serratia 39006}

Previously, Serratia 39006 mutants were identified which contained transposon insertions in regions sharing sequence similarity to the pstS and pstA genes from $E$. coli [29]. DNA sequencing analysis of this region revealed that Serratia 39006 possesses a complete pstSCAB-phoU operon, the organisation of which is consistent with other enteric bacteria in which a pst operon has been identified (Fig. 1A).

The Serratia 39006 pstS gene was predicted to encode a protein most similar to PstS from the enteric bacteria Erwinia carotovora ssp. atroseptica SCRI1043 (Eca 1043) (82\% identity/90\% similarity). The putative protein product encoded by pstC shared 90\% identity and 95\% similarity with PstC of Eca 1043. The pstA gene is predicted to encode a protein most similar to PstA of Eca 1043 (87\% identity/92\% similarity). The predicted protein encoded by pstB was most similar to PstB of Eca 1043 (88\% identity/91\% similarity). Finally, phoU was predicted to encode a protein most similar to PhoU of Eca 1043 (94\% identity/98\% similarity).

\section{Isolation and sequence analysis of phoBR mutants of Serratia 39006}

Mutations in the pstSCAB-phoU operon are thought to mimic growth in limiting phosphate, and hence result in constitutive activation of the Pho regulon [15]. We previ- 

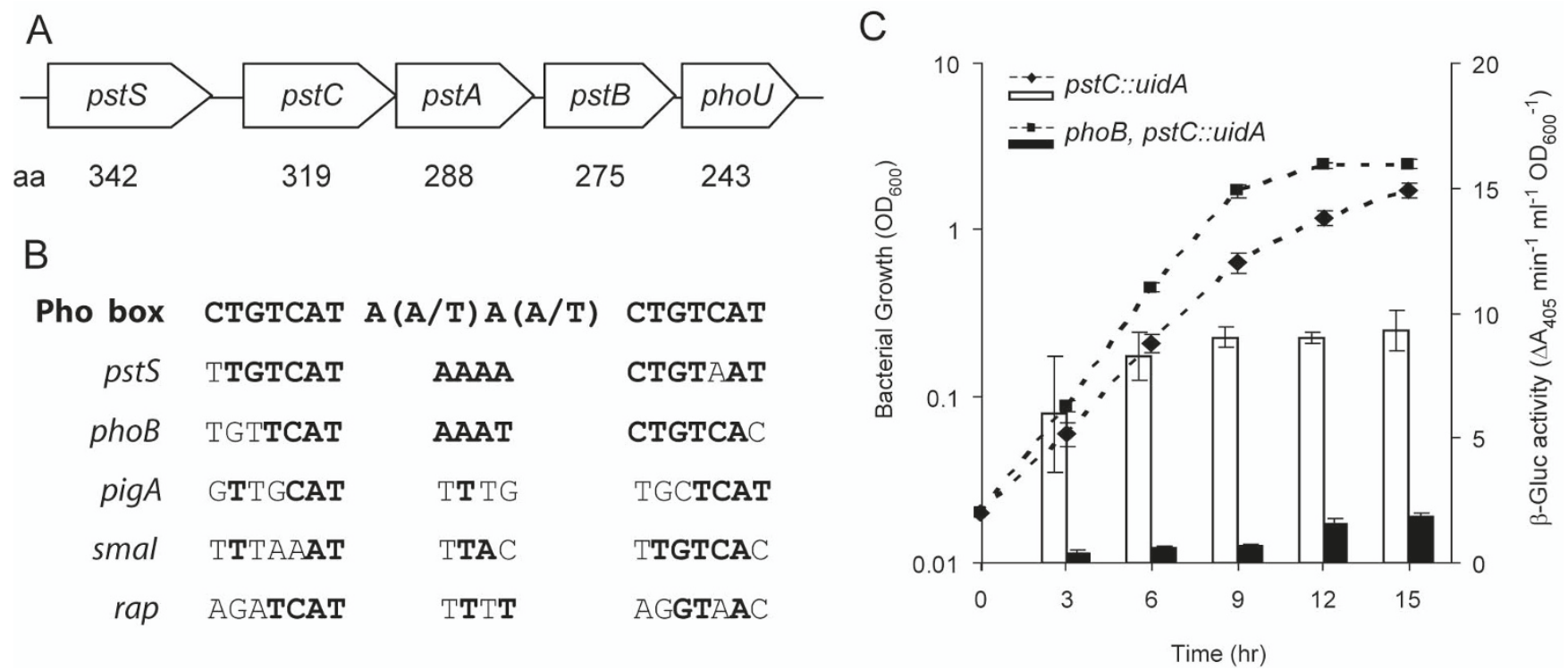

\section{Figure I}

The Serratia 39006 Pst transporter is regulated via PhoBR.. A) The Serratia 39006 pstSCAB-phoU genes. (B) Putative Pho boxes found upstream of the pstS, phoB, pigA, smal and rap genes in Serratia 39006. The E. coli Pho box consensus sequence is shown [10-12]. Conserved nucleotides are shown in bold. (C) $\beta$-Glucuronidase activity was assayed throughout growth in LB from a chromosomal pstC::uidA fusion in an otherwise WT background (NW20I; diamonds and open bars) or a phoB mutant background (NW202; squares and solid bars). Bars represent $\beta$-glucuronidase assays and dashed lines represent bacterial growth.

ously showed that Pig, Car and AHL production were increased in the pstS mutant [29]. A possible explanation for this effect is that pigA, carA and smaI are regulated via the Serratia 39006 Pho regulon.

Random transposon insertions in the phoBR operon were isolated based on their lack of hyperpigmentation when grown on $\mathrm{P}_{\mathrm{i}}$-limiting media. Growth on $\mathrm{P}_{\mathrm{i}}$-limiting media results in increased Pig production in the wild-type (WT; throughout this manuscript WT refers to the LacA parental strain) [29]. Potential phoBR mutants were then checked for their loss of alkaline phosphatase activity ( $p h o A$, encoding alkaline phosphatase, is a conserved Pho regulon gene [1,37]) and the sequence of the operon was determined, as described in Methods. The $p h o B$ gene was predicted to encode a 229 amino acid (aa) protein with highest similarity to PhoB from Eca 1043 (96\% identity/ $98 \%$ similarity). The phoR gene was located 28 bp downstream of $p h o B$, and was predicted to encode a 440 aa protein sharing the highest degree of similarity to Eca 1043 PhoR (87\% identity/90\% similarity).

\section{PhoB regulates expression of pstC in Serratia 39006}

In E. coli, the pst operon is activated via direct binding of PhoB to a conserved Pho box upstream of pstS [10-12]. As Serratia 39006 is a member of the Enterobacteriaceae, we identified potential Pho boxes based on the E. coli consen- sus sequence. A potential Pho box was identified within the pstS promoter region of Serratia 39006, centred 122 bp upstream of the pstS start codon (Fig. 1B). This suggested that, as could be expected based on regulation of the pst$S C A B$-phoU genes in other bacteria, the pstSCAB-phoU genes in Serratia 39006 may be regulated by PhoB. A putative Pho box was also identified upstream of $p h o B$ (Fig $1 B)$, centred 68 bp upstream of the phoB start codon, suggesting that phoBR may be auto-regulated via the putative Pho box.

$\beta$-Glucuronidase activity produced from a chromosomal pstC::uidA transcriptional fusion was measured in the presence or absence of a secondary mutation in phoB. The pstC::uidA fusion strain does not contain a functional Pst transporter and is therefore believed to mimic low phosphate conditions. These data showed that, in the presence of functional PhoB, pstC was expressed constitutively throughout growth (Fig. 1C). Expression was dramatically reduced following inactivation of $p h o B$, indicating that PhoB activates expression of the pst operon in Serratia 39006 (Fig. 1C).

\section{Insertions within phoBR abolish upregulation of secondary metabolism and QS in the pstS mutant}

It was hypothesised that the upregulation of Pig, Car and QS in a Serratia 39006 pst mutant was mediated via the 
PhoBR two-component system. Assessment of Pig, Car and QS phenotypes in pstS, phoB and pstS, phoR double mutants confirmed that $p h o B$ and $p h o R$ were responsible for the upregulation of secondary metabolism in a pstS mutant background. The pstS mutant was increased for Pig (9-fold), Car (2-fold) and AHL (2.5-fold) production compared with the WT (Fig. 2). However, the pstS, phoB and $p s t S$, phoR double mutants were restored to WT levels for Pig, Car and AHL production in LB (Fig. 2). Single phoB or phoR mutations had no effect on Pig, Car or AHL production (Fig. 2). As it has been previously shown that upregulation of Car in response to a pst mutation is mediated via the upregulation of QS [29], we focused on the effects on pigA and smaI expression for the remainder of this study.

\section{Insertions within phoBR abolish transcriptional upregulation of pigA and smal in the pstS mutant}

Phenotypic analysis showed that PhoBR are required for the upregulation of secondary metabolism and QS in response to mutation of the pstSCAB-phoU operon (described above). To confirm that these effects are exerted at the transcriptional level, primer extension analysis was used to assess levels of the pigA and smaI transcripts throughout growth in WT, pstS mutant and pstS, phoB double mutant strains. The abundance of pigA mRNA in the pstS, phoB double mutant was restored to levels similar to those displayed in WT Serratia 39006 (Fig. 3A). A chromosomal pigA::lacZ transcriptional fusion was used to confirm this result; a 3-fold increase in pigA transcription was observed in a pstS mutant, this was restored to WT levels following a secondary mutation in phoB or
phoR (Fig. 3B). The upregulation of smaI transcription in the pstS mutant was also abolished by a $p h o B$ mutation (Fig. 3C). This is consistent with the hypothesis that PhoB, either directly or indirectly, activates expression of pigA and smaI in response to constitutive phosphorylation by PhoR as a result of the pstS insertion.

\section{Insertions within pstSCAB-phoU result in increased transcription of rap}

A complex network of regulators controls secondary metabolism in Serratia 39006 [27]. Therefore, it was possible that the effects on Pig and AHL production, in response to a pst mutation, were mediated via one or more of these regulators. To test if the effect on smaI and pigA transcription was mediated through any of the known secondary metabolite regulators, the expression of chromosomal lacZ transcriptional fusions in pigP, pigQ, pigR, pigS, pigT, pigV, pigW, pigX, pigZ, rap and carR was assessed throughout growth in the presence or absence of a pstS::mini-Tn5Sm/Sp insertion (data not shown). No effect was seen on any of the regulatory genes except for rap. The expression of rap was increased by 1.4-fold in the pstS mutant (Fig. 4A). Rap is a putative SlyA/MarR-family transcriptional regulator. As expression of rap is known to be regulated by QS [28], the effect of a pstC mutation on expression of a rap::lac $Z$ transcriptional fusion was assessed in a smaI mutant background. A mutation within the pstSCAB-phoU operon was still able to activate rap transcription (1.5-fold increase), in the absence of functional smaI, indicating that this effect is via both QS dependent and -independent pathways (Fig. 4B).

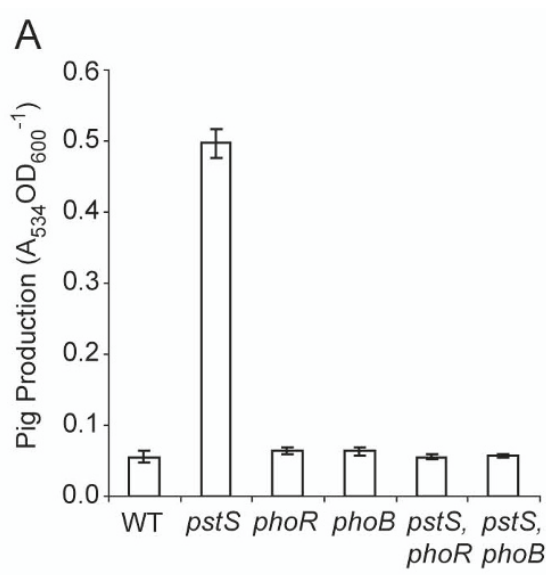

Pig

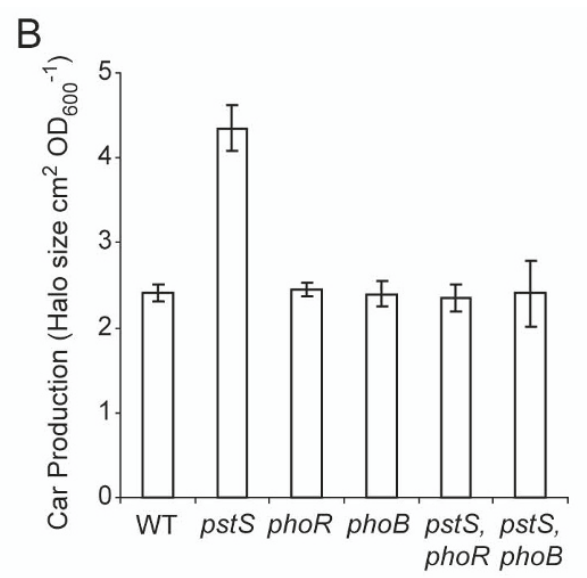

Car

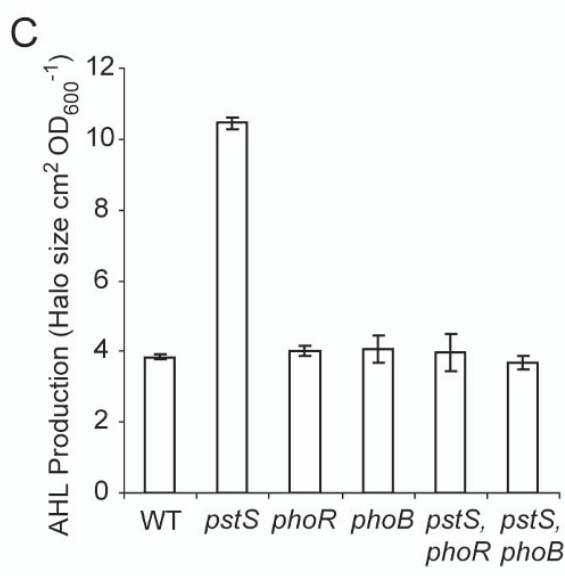

$\mathrm{AHL}$

Figure 2

The effects of a pstS mutation on secondary metabolism and QS are occurring via PhoBR. (A) Pig, (B) Car and (C) AHL production were measured from WT, pstS mutant (ROP2), phoR mutant (BRI), phoB mutant (BR9), pstS, phoR double mutant (PCF60) and pstS, phoB double mutant (PCF59) cells. Production was assayed from cells grown to early stationary phase in LB. 
A
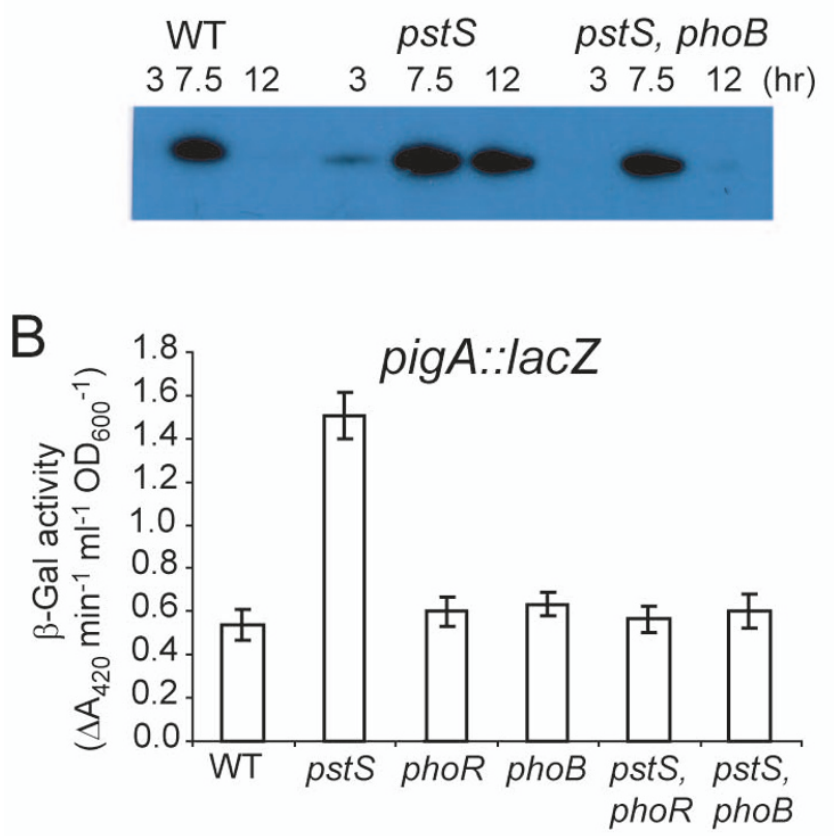

C

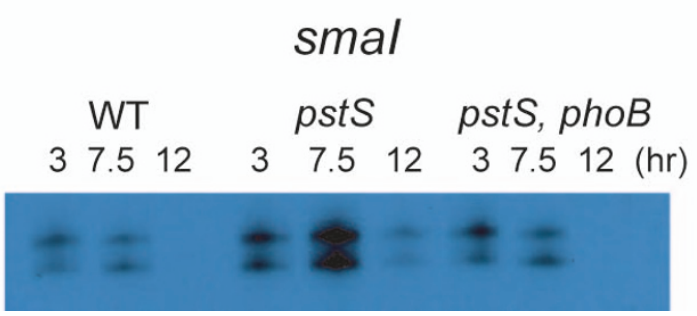

Figure 3

A pstS mutation effects transcription of pigA and smal via PhoBR. Primer extension analysis was used to measure the level of (A) pigA or (C) smal transcripts in WT, pstS mutant (ROP2), or pstS, phoB (RBR9) double mutant strains throughout growth in LB. (B) $\beta$-Galactosidase activity was measured from a chromosomal pigA::Iac $Z$ fusion in an otherwise WT background (NW60), or in pstS (PCF76), phoR (PCF75), phoB (PCF74), pstS, phoR double (PCF78) or pstS, phoB double (PCF77) mutant backgrounds. Activity was assayed from cells grown to early stationary phase in LB.

\section{PhoB activates expression from the pigA and rap promoters in an E. coli system}

To investigate the control of the pigA, rap and smaI promoters in more detail, an E. coli plasmid-based system was used (described in Methods). $\beta$-Galactosidase activity was measured from E. coli strains carrying the pigA, rap or smaI promoters, inserted upstream of a promoterless lac $Z$ gene (encoded by vectors pTA15, pTA14 or pTG27, respectively) in the presence or absence of Serratia $39006 \mathrm{PhoB}$, encoded by plasmid pTA74. Transcription from the pigA

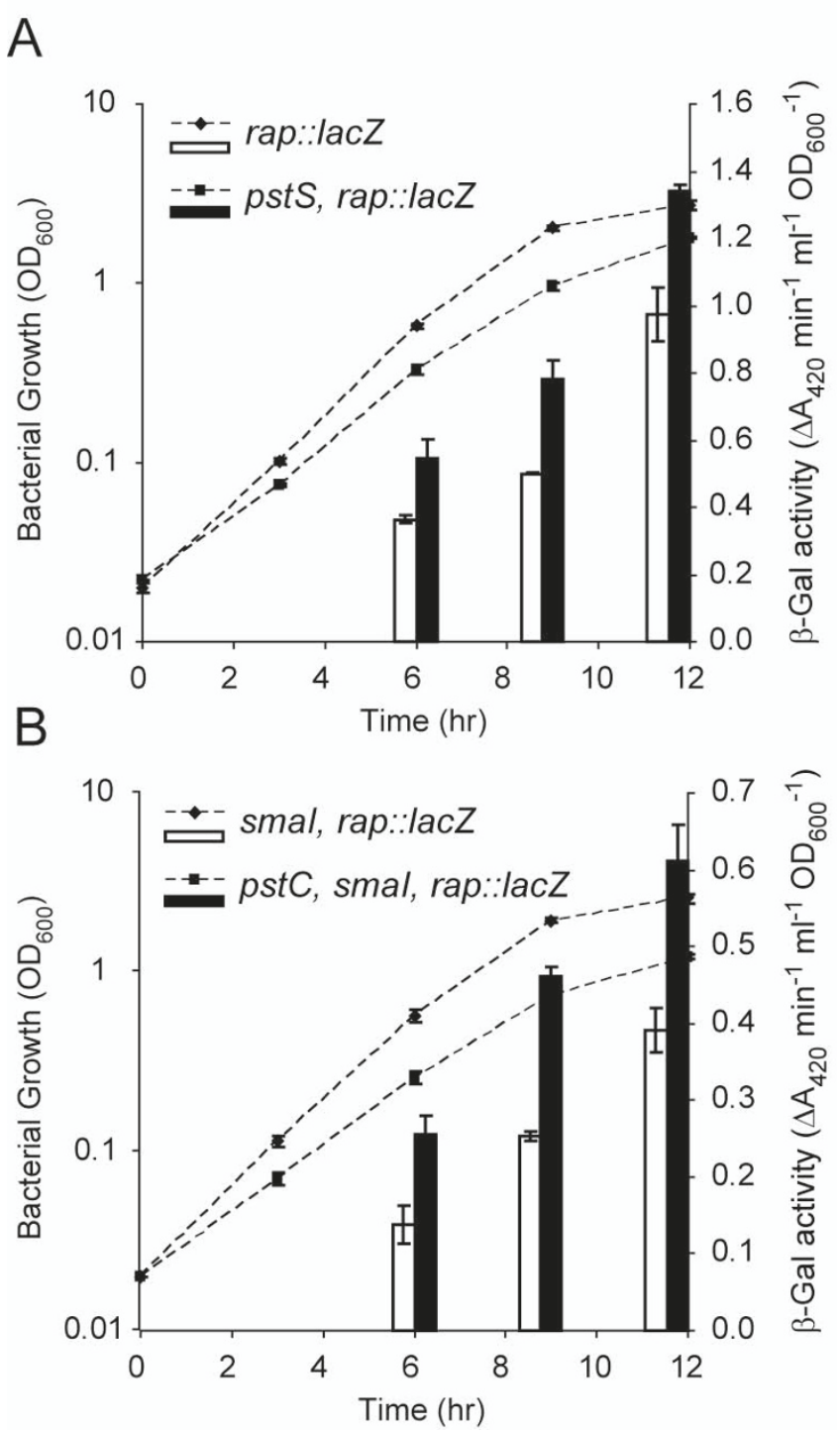

Figure 4

Expression of rap is activated following mutation of the pstSCAB operon. $\beta$-Galactosidase activity was assayed throughout growth from a chromosomal rap::IacZ fusion in (A) an otherwise WT background (RAPL;diamonds and open bars) or a pstS mutant background (PCF45; squares and solid bars), or (B) a smal (ISRL; diamonds and open bars) or pstC, smal (TG7I; squares and solid bars) mutant background. In both graphs, bars represent $\beta$-galactosidase assays and dashed lines represent bacterial growth.

and rap promoters increased in the presence of pTA74, indicating that these genes may be activated by PhoB (Fig. 5). Unfortunately, the level of expression from the smaI promoter was negligible in this system (data not shown). Therefore, it was not possible to determine whether PhoB 

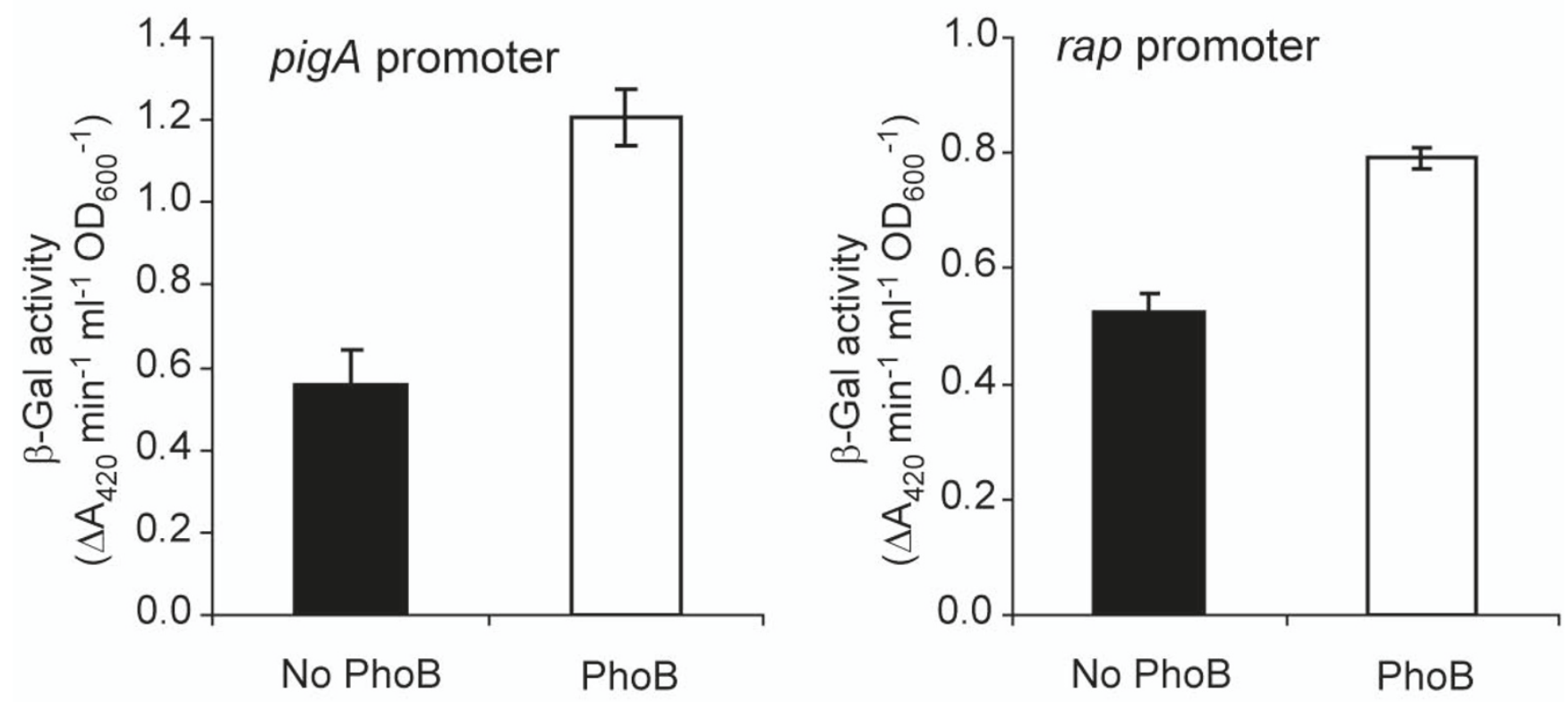

Figure 5

In E. coli, Serratia 39006 PhoB can activate expression from the pigA and rap promoters. $\beta$-Galactosidase activity was measured from $E$. coli cells grown in LB carrying plasmid PTAI 5 or PTAI4 (containing the pigA or rap promoters respectively cloned upstream of a promoterless lacZ gene) and either an empty vector control (pQE-80L) (solid bar) or pTA74, encoding PhoB (unfilled bar).

was modulating transcription from the smaI promoter. In the E. coli system, the degree of activation from both the pigA and rap promoters in the presence of PhoB is comparable with the levels of activation observed using chromosomal pigA::lacZ and rap::lacZ transcriptional fusions as a result of pstS/pstC mutation in Serratia 39006 (Fig. 3B \& Fig. 4). Putative weak Pho boxes were identified within the promoter regions of pigA and smaI, overlapping the predicted -35 sequences and centred 28 bp and $34 \mathrm{bp}$, respectively, upstream of the transcriptional start sites, which were previously mapped by primer extension [29] (Fig. 1B). A putative weak Pho box was also identified within the rap promoter, centred 148 bp upstream of the rap start codon (Fig. 1B). The presence of putative Pho boxes suggest that PhoB may directly activate expression of pigA, smaI and rap, although this has not yet been shown experimentally. In the $E$. coli reporter assays described, it is possible that Serratia 39006 PhoB may show activity in the absence of the cognate Serratia 39006 histidine kinase, PhoR, due to cross-regulation by noncognate E. coli histidine kinases, or as a result of low level activity of the unphosphorylated Serratia 39006 PhoB.

\section{$P_{i}$ regulates secondary metabolism and QS in Serratia 39006}

In other species, PhoBR upregulates expression of multiple genes when the cell is starved for $P_{i}$. As $P_{i}$ has been shown to control secondary metabolism in multiple species [17], we investigated whether secondary metabolism and QS in Serratia 39006 were also modified by $\mathrm{P}_{\mathrm{i}}$ limitation. Growth of Serratia 39006 in phosphate-limiting medium (PL medium) without the addition of $5 \mathrm{mM}$ $\mathrm{KH}_{2} \mathrm{PO}_{4}$ resulted in an increase in Pig (6-fold) and AHL (2-fold) production (Fig. 6A \&6B), reminiscent of the effects of $p s t S$ mutations. $\beta$-Galactosidase activity from strains containing chromosomal pigA::lacZ, smaI::lacZ and rap::lac $Z$ fusions grown in $\mathrm{PL}$ medium without the addition of $5 \mathrm{mM} \mathrm{K \textrm {K } _ { 2 }} \mathrm{PO}_{4}$ was also assessed. $\mathrm{P}_{\mathrm{i}}$ limitation resulted in increased transcription of pigA (2-fold) and smaI (5-fold) compared with $\mathrm{P}_{\mathrm{i}}$ replete conditions (Fig. 7A \&7B), although there was not a clear increase in rap transcription (Fig. 7C). These experiments demonstrate that low $\mathrm{P}_{\mathrm{i}}$, like pstSCAB-phoU mutations, controls the transcription of pigA and smaI to up-regulate secondary metabolism and QS. However, in each instance, the fold increase in response to $P_{i}$ limitation is lower (by approxi- 


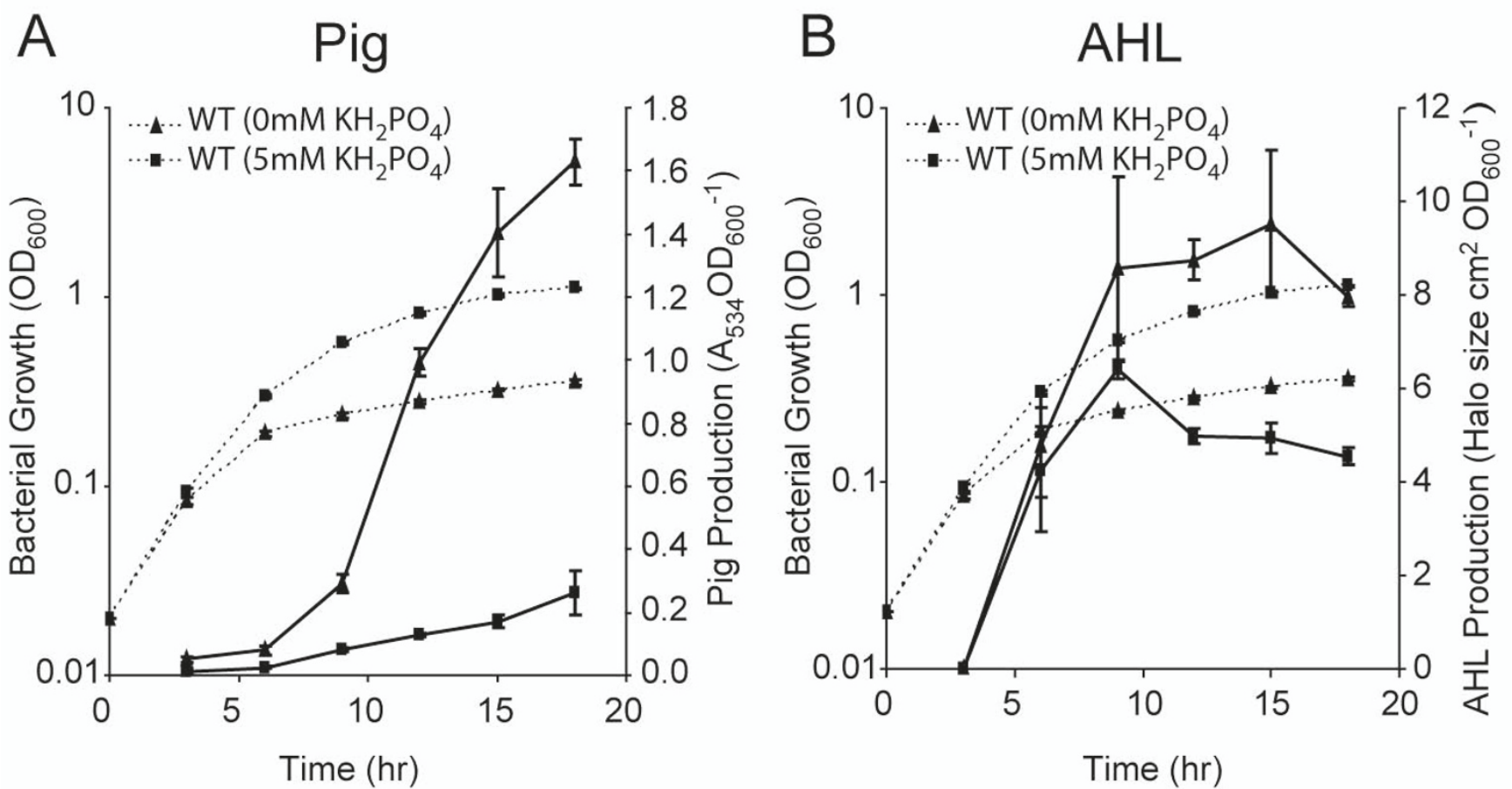

Figure 6

$\mathbf{P}_{\mathrm{i}}$ limitation affects secondary metabolism and QS. (A) Pig and (B) AHL production in WT cells were measured throughout growth in phosphate-limiting medium with (squares) or without (triangles) the addition of $5 \mathrm{mM} \mathrm{KH}_{2} \mathrm{PO}_{4}$. In all graphs, solid lines represent Pig or $\mathrm{AHL}$ assays and dashed lines represent bacterial growth.

A

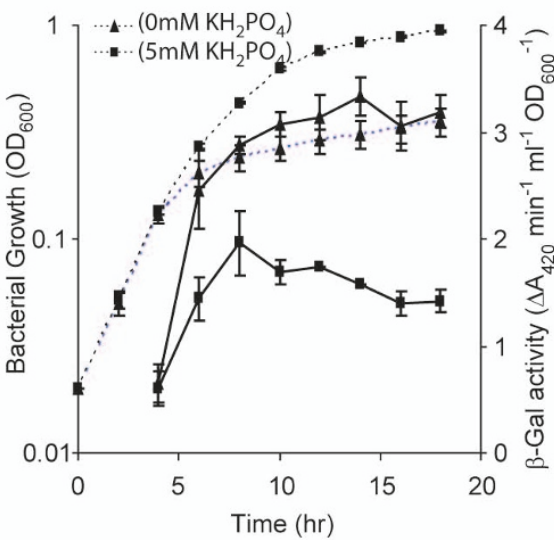

B smal::IacZ

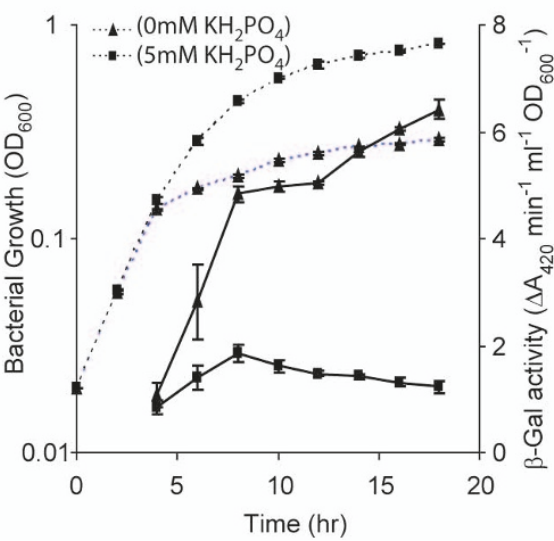

C

rap::lacZ

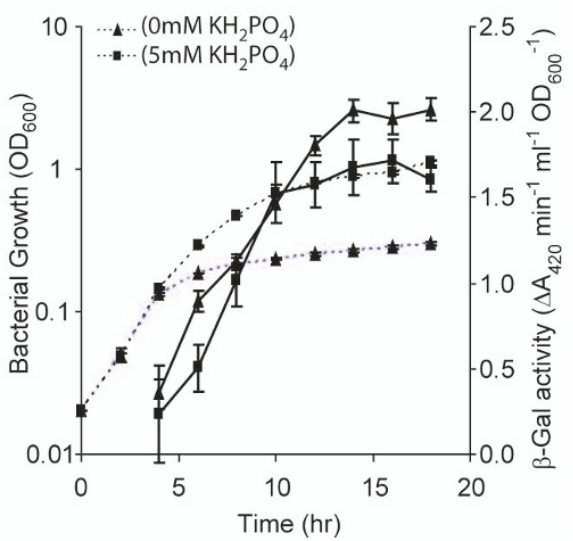

Figure 7

The effect of $P_{i}$ limitation on pigA, smal and rap transcription. $\beta$-Galactosidase activity was measured from a chromosomal (A) pigA::lacZ (MCP2L), (B) smal::lacZ (LCI3) or (C) rap::IacZ (RAPL) strain throughout growth in phosphate-limiting medium with (squares) or without (triangles) the addition of $5 \mathrm{mM} \mathrm{K \textrm {H } _ { 2 }} \mathrm{PO}_{4}$. In all graphs, solid lines represent $\beta$-galactosidase assays and dashed lines represent bacterial growth. 
mately 35\%) than that observed in a pst mutant. As the increase in rap transcription in a pst mutant is below 2fold, a lesser change, in response to $P_{i}$ limitation, may be below the level of detection.

We predicted that a pstS mutation would be epistatic to the effects of $\mathrm{P}_{\mathrm{i}}$ on secondary metabolism and QS. In a pstS mutant, $\mathrm{P}_{\mathrm{i}}$ limitation did not result in an increase in maximal Pig production (Fig. 8A), although slightly premature production of Pig was observed (data not shown). In addition, $\mathrm{P}_{\mathrm{i}}$ limitation resulted in only a small (1.3-fold) increase in AHL production in a pstS mutant (Fig. 8B). Taken together, the data suggest that in Serratia 39006, as in other bacteria, mutation of pstS mimics the effect of $\mathrm{P}_{\mathrm{i}^{-}}$ limiting media. However, other mechanisms also appear to play a role, facilitating the small increase in AHL production observed in response to $\mathrm{P}_{\mathrm{i}}$ limitation despite the absence of a functional PstSCAB-PhoU system.

\section{Discussion}

There are multiple studies identifying environmental factors that effect Pig production in Serratia spp., including the effects of salt concentration, temperature, oxygen availability and multiple metal ion concentrations [27]. However, the molecular mechanism underlying most of these responses has not been elucidated. Here, we investigate the molecular mechanism by which $\mathrm{P}_{\mathrm{i}}$ limitation affects secondary metabolism in the enteric bacteria Serratia 39006.

It was previously shown that a pstS mutation in Serratia 39006 resulted in the upregulation of QS and secondary metabolism [29]. Here, we demonstrate that these effects are occurring via the PhoBR two-component system, since a secondary mutation in phoBR abolished the effects of a pstS mutation. In addition, we confirm that QS and secondary metabolism are upregulated in response to $\mathrm{P}_{\mathrm{i}}$ limitation, and that this is occurring primarily via the PstSCAB-PhoU transport system. We also demonstrate that expression of rap is upregulated in response to a pstS mutation. Rap is an activator of Pig and Car, and a repressor of surfactant production and swarming motility, in Serratia $39006[19,29]$. Rap shares similarity with the SlyA/MarR-family global transcription factor, RovA, which regulates genes required for host colonization in Yersinia spp. [32-34]. Therefore, our results indicate that three global transcriptional regulators, Rap, SmaR and PhoB, are involved in mediating the effects of $\mathrm{P}_{\mathrm{i}}$ limitation on secondary metabolism in Serratia 39006.

A mutation of the pstSCAB-phoU genes resulted in a clear increase in Pig and AHL production, and a clear increase in pigA, smaI and rap transcription. However, following $\mathrm{P}_{\mathrm{i}}$ limitation, the effects on secondary metabolism and gene
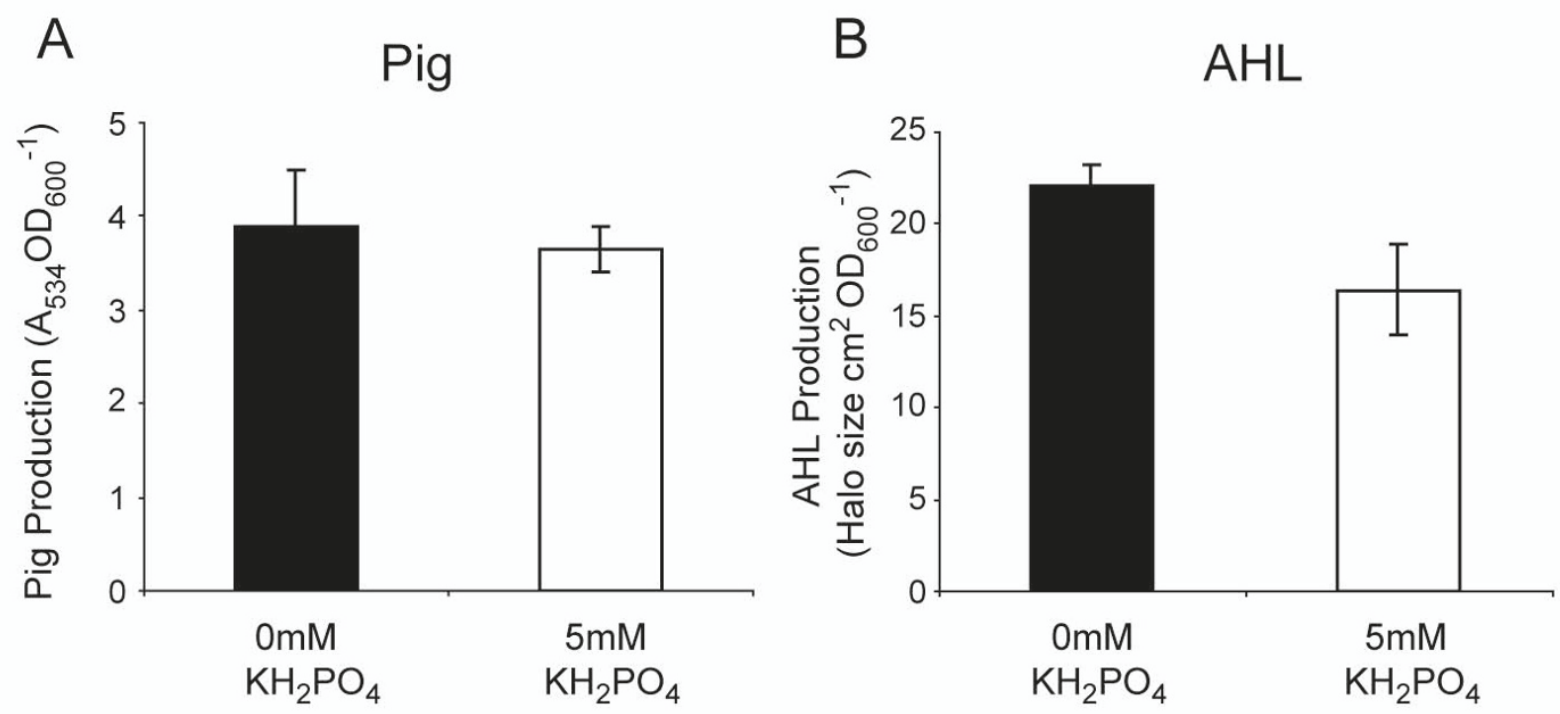

Figure 8

A pstS mutant is largely unresponsive to $\mathbf{P}_{\mathrm{i}}$ limitation. (A) Pig and (B) $\mathrm{AHL}$ production was measured from a pstS mutant (ROP2) grown to early stationary phase in phosphate-limiting medium with (open bars) or without (solid bars) the addition of $5 \mathrm{mM} \mathrm{KH}_{2} \mathrm{PO}_{4}$. 
expression were less dramatic. The degree of activation of Pig and AHL production, and pigA transcription, was approximately $35 \%$ lower following $\mathrm{P}_{\mathrm{i}}$ limitation than the levels of activation observed in a pstS mutant. In addition, a clear increase in rap transcription was not observed following $\mathrm{P}_{\mathrm{i}}$ limitation. It is possible that this reduced effect is due to the fact that a pstS mutant is constitutively mimicking extreme $\mathrm{P}_{\mathrm{i}}$ limitation. However, when WT cells are transferred to phosphate limiting media, there may be phosphate carry over from the initial inoculum, and the cells may utilise existing intracellular phosphate stores, for example inorganic polyphosphate, before phosphate starvation occurs. As the increase in rap transcription in a pstS mutant is below 2 -fold, we believe that a $35 \%$ reduction in activation, in response to $P_{i}$ limitation, may be undetectable. An alternative explanation could be that rap is induced via PhoBR, but not in response to $P_{\mathrm{i}}$ limitation. Previously, PhoBR has been shown to activate expression of the asr (acid shock RNA) gene, but $P_{\mathrm{i}}$ limitation did not activate asr expression [38]. In addition, there is also evidence that PhoB can be activated by non-partner histidine kinases, in the absence of PhoR [39]. This has lead to the hypothesis that PhoBR may activate genes in response to a variety of environmental cues, in addition to $P_{\mathrm{i}}$ limitation [39].

It may not be entirely accurate to describe the effect of a pstS mutation, or $\mathrm{P}_{\mathrm{i}}$ limitation, on QS as 'upregulation'. For QS to function correctly, it is the absolute concentrations of the AHL signal molecule that is critical, not the amount per cell [30]. Due to the growth defect observed following a pstS mutation or $\mathrm{P}_{\mathrm{i}}$ limitation, the amount of AHL per cell is increased, but the absolute value remains comparable to $\mathrm{WT} / \mathrm{P}_{\mathrm{i}}$ excess conditions. Therefore, it may be more accurate to state that the upregulation of smaI transcription, following $p s t S$ mutation or $\mathrm{P}_{\mathrm{i}}$ limitation, allows maintenance of $\mathrm{QS}$ regulon control despite the reduced growth rate. This idea is supported by the fact that although $c a r R$, pigQ, pigR and rap are all regulated by QS in Serratia $39006[28,29]$, only rap transcription is upregulated in response to a $p s t S$ mutation. Our experiments indicate that, in response to a pst mutation, rap is activated independently of QS, and that activation may be mediated via PhoB.

Activation of carA expression, following pstS mutation, was previously reported to be dependent on the upregulation of QS [29]. However, as Rap is also an activator of carA transcription [29], it is possible that Rap, rather than $\mathrm{QS}$, is responsible for the activation of carA following a pstS mutation. We propose that a dual mechanism, involving (1) the alleviation of SmaR repression at lower cell density, via upregulation of smaI, and (2) increased levels of Rap via PhoB mediated transcriptional activation, is responsible for the increase in carA expression fol- lowing pstS mutation. In the absence of AHL (and hence constitutive SmaR repression), carA transcription is essentially abolished [29] and hence, further activation by Rap, in response to a $p s t S$ mutation, might not be possible.

Based on our data, we propose a model by which $\mathrm{P}_{\mathrm{i}}$ limitation results in upregulation of secondary metabolism via multiple inter-linked pathways (Fig. 9). In response to $P_{i}$ limitation, or following mutation of the pstSCAB genes, PhoB is activated by phosphorylation $[9,15,16]$. PhoB P can then activate expression of genes involved in the Serratia phosphate response which includes smaI, pigA and rap. Activation of pigA expression causes increased Pig production. Upregulation of smaI allows appropriate derepression by SmaR $[28,29]$. This allows activation of pigA, carA and rap transcription. Rap, which is activated via QS and the phosphate response, can then further activate car $A$ and pigA transcription. This results in upregulation of both Car and Pig production via multiple pathways.

Multiple studies have linked $P_{i}$ limitation to enhanced secondary metabolite production [17]. However, the complex molecular mechanisms underlying phosphatemediated regulation have proven difficult to elucidate. Extensive studies in Streptomyces species have shown that PhoPR (PhoBR) activates secondary metabolism in response to $P_{i}$ limitation, including biosynthesis of undecylprodigiosin, a tripyrrole closely related to Pig $[40,41]$. However, in Streptomyces, inactivation of PhoP or deletion of phoPR also activates secondary metabolism [41]. In contrast, deletion of phoB and/or phoR in Serratia 39006 had no impact on secondary metabolism, demonstrating clear differences between the regulatory mechanisms employed by these distantly related bacteria. Although the requirement for increased secondary metabolism under conditions of phosphate limitation is unclear, it has been proposed that enhanced secondary metabolism allows the production of compounds which may, for example, directly antagonise other microorganisms or act as signalling molecules, thereby providing producing organisms with a competitive advantage under nutrient deprived conditions $[40,42,43]$.

\section{Conclusion}

In conclusion, we have established that via the global transcriptional regulators $\mathrm{PhoB}, \mathrm{SmaR}$ and Rap, multiple inter-linked pathways are acting to upregulate secondary metabolism in Serratia 39006 under conditions of $\mathrm{P}_{\mathrm{i}}$ limitation, highlighting the importance of Pig and Car production under these conditions.

\section{Methods}

\section{Bacterial strains, plasmids, phage and culture conditions}

Bacterial strains and plasmids are listed in Additional File 1[44-49]. Serratia sp. ATCC 39006 derivative strains were 


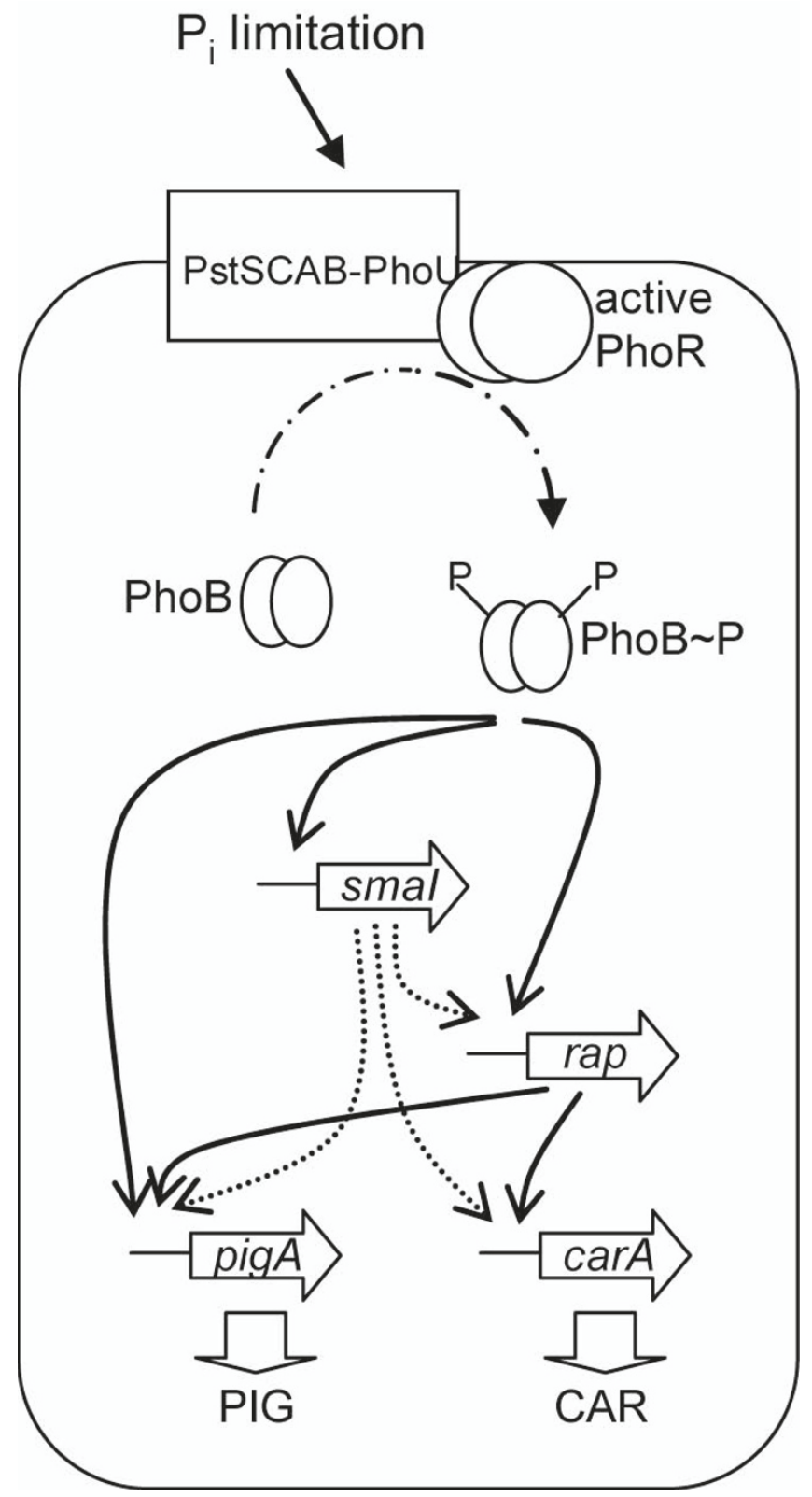

Figure 9

The proposed mechanism by $\mathbf{P}_{\mathrm{i}}$ limitation can upregulate secondary metabolism in Serratia 39006. In response to $\mathrm{P}_{\mathrm{i}}$ limitation (or pstS mutation), PhoR activates PhoB by phosphorylation. Active PhoB can then activate transcription of smal, pigA and rap (indicated using solid arrows). Upregulation of smal results in activation of the QS regulated genes (pigA, carA and rap), via AHL mediated SmaR derepression (indicated using dashed arrows). Rap then further activates carA and pigA expression (indicated using solid arrows). This results in upregulation of Pig and Car production.

grown at $30^{\circ} \mathrm{C}$ and E. coli strains were grown at $37^{\circ} \mathrm{C}$ in Luria broth (LB; $5 \mathrm{~g} \mathrm{l}^{-1}$ yeast extract, $10 \mathrm{~g} \mathrm{l}^{-1}$ bacto tryptone and $\left.5 \mathrm{~g} \mathrm{l}^{-1} \mathrm{NaCl}\right)$, minimal media $\left(0.1 \% \mathrm{w} / \mathrm{v}\left(\mathrm{NH}_{4}\right)_{2} \mathrm{SO}_{4^{\prime}}\right.$ $0.41 \mathrm{mM} \mathrm{MgSO}{ }_{4}, 0.2 \% \mathrm{w} / \mathrm{v}$ glucose, $40 \mathrm{mM} \mathrm{K} \mathrm{HPO}_{4}$, $14.7 \mathrm{mM} \mathrm{KH}_{2} \mathrm{PO}_{4}, \mathrm{pH}$ 6.9-7.1) or in phosphate limiting (PL) media $\left(0.1 \% \mathrm{w} / \mathrm{v}\left(\mathrm{NH}_{4}\right)_{2} \mathrm{SO}_{4}, 0.41 \mathrm{mM} \mathrm{MgSO} \mathrm{Mg}_{4}\right.$ $0.2 \% \mathrm{w} / \mathrm{v}$ glucose, $0.1 \mathrm{M}$ HEPES, $\mathrm{pH} 6.9-7.1 \pm 5 \mathrm{mM}$ $\mathrm{KH}_{2} \mathrm{PO}_{4}$ ) in shake flasks at $300 \mathrm{rpm}$, or on plates supplemented with $1.5 \%(\mathrm{w} / \mathrm{v})$ agar (LBA). For the phoBR mutagenesis screen, Serratia 39006 was grown on PGM agar plates ( $5 \mathrm{~g} \mathrm{l}^{-1}$ bacto peptone, $1 \% \mathrm{v} / \mathrm{v}$ glycerol and $1.5 \% \mathrm{w} /$ $\mathrm{v}$ agar). Bacterial growth $\left(\mathrm{OD}_{600}\right)$ was measured in a Unicam Hedios spectrophotometer at $600 \mathrm{~nm}$. When required, media were supplemented with antibiotics at the following final concentrations; kanamycin $50 \mu \mathrm{g} \mathrm{ml}^{-1}$ $(\mathrm{Km})$, spectinomycin $50 \mu \mathrm{g} \mathrm{ml}^{-1}$ (Sp), ampicillin $100 \mu \mathrm{g}$ $\mathrm{ml}^{-1}$ (Ap), and tetracycline $35 \mu \mathrm{g} \mathrm{ml}^{-1}$ (Tc). The generalised transducing phage $\varphi \mathrm{OT} 8$ was used for transduction of chromosomal mutations as described previously [25].

\section{DNA manipulations}

All molecular biology techniques, unless stated otherwise, were performed by standard methods [50]. Oligonucleotide primers were obtained from Sigma Genosys and are listed in Table 1. DNA sequencing was performed at the DNA Sequencing Facility, Department of Biochemistry, University of Cambridge, analysed using GCG (Genetics Computer Group, University of Wisconsin) and compared with GenBank DNA or non-redundant protein sequence databases using BLAST [51].

\section{Sequencing of the pstSCAB-phoU operon}

Preliminary sequence analysis indicated the mini-Tn5Sm/ Sp insertions in strains ROP2 and KHC5 were in pstS and $p s t A$ respectively [29]. To determine the full sequence of pstS and its surrounding genes, a Serratia 39006 PstI subgenomic library was created in pBluescript II KS+. One clone containing pstS was analysed further and was named pPST1. The pst region was sequenced via a 'primer walking' technique using primers PST1, PST2, PST3, PST4, PST5, PSTSLN, PSTSRN. To complete the pstSCAB-phoU operon, a $2.1 \mathrm{kbp}$ region of pstSCA was PCR amplified with the primers NW244 and NW245, and then sequenced using primers NW244, NW245, NW246 and NW247. Random primed PCR was used to extend the phoU sequence obtained from primer walking of pPST1, as described previously [48]. Gene specific primer NW250 was used in two separate random primed PCR reactions, one with PF106, PF107, PF108 [48], and a second with NW225, NW226, NW227. The products generated were then amplified with the nested primer PF109 or NW251, respectively and the resulting PCR products sequenced with primer NW251.

\section{Transposon mutagenesis screen for phoBR mutants}

To isolate phoBR mutants, Serratia 39006 strain LacA was subjected to a random transposon mutagenesis by conju- 
Table I: Oligonucleotide primers used in this study

\begin{tabular}{|c|c|c|c|}
\hline Name & 5'-3' sequence & Description & Restriction site \\
\hline HS34 & GCTGACTCATAAATATCTGACTG & pigA, primer extension oligo & \\
\hline HS36 & GCGAAAATAGCTCGGCTGATCTC & smal, primer extension oligo & \\
\hline HS60 & GTCTATATCGGCATCTGTTCC & carA, primer extension oligo & \\
\hline KML & CCAGTAAGTTTTCCAGTAGGTGG & F primer for $\mathrm{Km}^{\mathrm{R}}$ gene of miniTn $5 \mathrm{Km} \mathrm{I}$ & \\
\hline KMR & CCGAGCTTGGTACCCAGTC & $\mathrm{R}$ primer for $\mathrm{Km} \mathrm{R}^{\mathrm{R}}$ gene of miniTn $5 \mathrm{Km} \mathrm{I}$ & \\
\hline NW225 & GACCACACGTCGACTAGTGCNNNNNNNNNACTG & Random primed PCR primer I & \\
\hline NW226 & GACCACACGTCGACTAGTGCNNNNNNNNNATGAC & Random primed PCR primer 2 & \\
\hline NW227 & GACCACACGTCGACTAGTGCNNNNNNNNNGTCTC & Random primed PCR primer 3 & \\
\hline NW244 & CGTCTGCCAGGTGCTATTGGTTATG & pstSCAB region sequencing primer & \\
\hline NW245 & GGATAACGAAGTGAACAGCAAC & pstSCAB region sequencing primer & \\
\hline NW246 & GCATCCTGGCCGAGCATACAGAAG & pstSCAB region sequencing primer & \\
\hline NW247 & GCGACGCATGCGGATAAGCTCTG & pstSCAB region sequencing primer & \\
\hline NW250 & CATTACTGCGATGCACAATCAG & phoU sequencing primer & \\
\hline NW25 I & GTGACGATTGATGAAGCTTGTG & phoU sequencing primer & \\
\hline OTG 124 & ATCAGAGAATTCTACTAATTGGAGTCATTACCG & F primer for PTG27, smal promoter construct & EcoRI \\
\hline OTGI 25 & ATCAGAAAGCTTAGTCTATCATTATAGCGTTCC & $\mathrm{R}$ primer for $\mathrm{PTG} 27$, smal promoter construct & HindIII \\
\hline PF42 & GCATAAGCTTCCATCACTACTCC & R primer for $\mathrm{PTA} \mid 4$, rap promoter construct & HindllI \\
\hline PF43 & GTAAGAATTCGCGATGTTCAGAAAC & F primer for PTA 14 , rap promoter construct & EcoRI \\
\hline PFI54 & $\begin{array}{l}\text { GATGAATTCAGGAGGACAGGGATGGCAAGACGTATTTT } \\
\text { G }\end{array}$ & F primer for $\mathrm{pTA74,}$ PhoB expression construction & EcoRI \\
\hline PFI55 & TCTAAGCTTCAGTAACGCGTCGAG & $\mathrm{R}$ primer for $\mathrm{PTA} 74, \mathrm{PhoB}$ expression construction & HindIII \\
\hline PFI80 & TTTGAATTCGTTAGTTTGGGAGATTTTC & F primer for sequencing phoR & EcoRI \\
\hline PFI82 & TTTAAGCTTGCTGCGGGACGC & $\mathrm{R}$ primer for sequencing phoR & HindIII \\
\hline PHORL & GCGTTAGTTTGGGAGATTTTC & F phoR primer & \\
\hline PHORR & СTCCCAAACTAACGCTGTC & $\mathrm{R}$ phoR primer & \\
\hline PSTI & CAGCGTCTGCCAGGTGC & pstS sequencing primer & \\
\hline PST2 & GTCCACGTTGCTGAG & pstA sequencing primer & \\
\hline PST3 & CCAGCTTTACCCAGAGCAACATG & pstB sequencing primer & \\
\hline PST4 & CAGAGTGTAGTTTGCAGG & pstS sequencing primer & \\
\hline PST5 & CGAGCAACAGCCAGTAG & pstA sequencing primer & \\
\hline PSTSLN & CAACAGGATAAAGGTAGTGGAGG & pstS sequencing primer & \\
\hline PSTSRN & CTGCACGGTCTTGGTCG & pstS sequencing primer & \\
\hline T3 & CGCGCAATTAACCCTCACTAAAG & pBluescript II KS+ sequencing primer & \\
\hline $\mathrm{T7}$ & GCGCGTAATACGACTCACTATAG & pBluescript II KS+ sequencing primer & \\
\hline
\end{tabular}

gation with E. coli S17-1 $\lambda$ pir harbouring plasmid pUTmini-Tn5Km1 as described previously [25]. Ten thousand mutants were picked onto glucose minimal medium plates and replica-plated onto PGM agar Colonies that did not exhibit a hyper-pigmented phenotype were selected, based on the rationale that if hyper-pigmentation was not induced in response to $\mathrm{P}_{\mathrm{i}}$ limitation, it might be due to an insertion in phoBR (strains BR1 and BR9 were isolated using this screen). The pstS::miniTn5Sm/Sp was transduced into non- $\mathrm{P}_{\mathrm{i}}$ responsive mutants, and non-hyperpigmented mutants were then selected (strains RBR1 and RBR9 were selected following this screen). This suggested that these uncharacterised insertions had disrupted a regulatory element(s) common to $p s t S$ mutants and $\mathrm{P}_{\mathrm{i}}$ limitation effects. The possibility that phoBR had been disrupted was investigated further by measuring alkaline phosphatase activity, encoded by phoA, which is a well conserved member of enteric Pho regulons [1]. Mutants RBR1 and RBR9 did not produce elevated levels of alkaline phosphatase as observed in the pstS mutant (data not shown). Sequence analysis, described below, confirmed that the insertions in BR1 and BR9 were within phoR and phoB respectively.

\section{Sequencing of the phoBR operon}

To determine the site of the transposon insertion in strain BR1, chromosomal DNA was digested with EcoRV and ligated into pBluescript II KS+. The ligation was used as template in a single-primer-site PCR using primers KML and KMR that anneal to the $5^{\prime}$ and $3^{\prime}$ ends of mini$\mathrm{Tn} 5 \mathrm{Km} 1$ respectively in combination with primers $\mathrm{T} 3$ and T7. Sequencing of the resultant PCR products revealed that BR1 contained an insertion within a gene similar to phoR from E. coli. A further PCR using chromosomal DNA from the BR9 mutant with primers PHORL and PHORR (homologous to phoR $5^{\prime}$ and $3^{\prime}$ ends) and primers KML and KMR demonstrated that BR9 contained an insertion within a gene with similarity to $p h o B$ from $E$. coli. To further confirm the phoBR sequence, PCR products of $p h o B$ and $p h o R$ were generated with primer pairs PF154/PF155 
and PF180/PF182 respectively and sequenced on both strands from independent products.

\section{Construction of a plasmid (PTA74) that expresses native PhoB}

A construct that enabled expression of native, untagged PhoB was created as outlined below. The $p h o B$ gene was amplified by PCR, using primers PF154 and PF155, which contain EcoRI and HindIII restriction sites, respectively. Additionally, primer PF154 contains a consensus ribosome-binding site (RBS, AGGAGGA). The PCR fragment of phoB was cloned into pQE-80L, previously digested with the enzymes EcoRI and HindIII. The resulting plasmid, pTA74, was confirmed by DNA sequencing. Expression of plasmid pTA74 in E. coli was induced with 1 mM IPTG.

\section{Construction of promoter::lacZ fusions and assay conditions}

Plasmid pTA15 was constructed as described previously [48]. The rap and smaI promoter regions were cloned into the promoterless lacZ plasmid pRW50 [49] to give the plasmid constructs pTA14 and pTG27, respectively. Plasmid pTG27 was constructed by cloning an EcoRI/HindIII digested PCR product (generated using forward primer OTG124 and reverse primers OTG125) into EcoRI/HindIII digested pRW50. Plasmid pTA14 was constructed by cloning an EcoRI/HindIII digested PCR product (generated using forward primer PF43 and reverse primer PF42) into EcoRI/HindIII digested pRW50. All constructs were confirmed by DNA sequencing.

Promoter activity assays were performed in E. coli DH5a cells as described in [48]. Briefly, DH5 $\alpha$ cells were transformed with the promoter::lacZ construct (pTA14, pTA15 or pTG27) and either pTA74 (encoding native PhoB) or the empty vector control, $\mathrm{pQE}-80 \mathrm{~L}$. The resulting strains were grown in LB containing Ap, Tc and $1 \mathrm{mM}$ isopropyl$\beta$-D-thiogalactopyranoside (IPTG). At late exponential phase, $1 \mathrm{ml}$ samples were assayed for $\beta$-galactosidase activity.

\section{Prodigiosin, carbapenem, AHL, $\beta$-galactosidase, $\beta$ - glucuronidase and alkaline phosphatase assays}

The assays for Pig and Car were performed as described previously [29]. Pig production was plotted as $\left(\mathrm{A}_{534} \mathrm{ml}^{-1}\right.$ $\mathrm{OD}_{600}{ }^{-1}$ ). Detection of AHLs was performed using the Serratia LIS bioassay described in [25]. $\beta$-Galactosidase activity was determined as described previously [28] and was represented as $\left(\Delta \mathrm{A}_{420} \mathrm{~min}^{-1} \mathrm{ml}^{-1} \mathrm{OD}_{600}{ }^{-1}\right)$. $\beta$-Glucuronidase activity was determined as for $\beta$-galactosidase activity except that reactions were performed in GUS buffer (50 $\mathrm{mM} \mathrm{NaPO}_{4}, 1 \mathrm{mM}$ EDTA, $5 \mathrm{mM}$ DTT, pH 7.0), using the substrate $p$-nitrophenyl $\beta$-glucuronide (PNPG; $10 \mathrm{mM}$ ), and measured at $\mathrm{A}_{405}$. $\beta$-Glucuronidase activity was represented as $\left(\Delta \mathrm{A}_{405} \mathrm{~min}^{-1} \mathrm{ml}^{-1} \mathrm{OD}_{600}{ }^{-1}\right)$. Alkaline phos- phatase activity was assayed as described previously [52]. Results presented are the mean \pm the standard deviation of three independent experiments, unless stated otherwise.

\section{Primer Extension and RNA studies}

RNA was extracted from Serratia 39006 and primer extension analysis for the pigA and smaI transcripts was performed as described previously [28,29]. All primer extension reactions were performed with $25 \mu \mathrm{g}$ of total RNA and 0.2 pmol of the appropriate ${ }^{32}$ P-labelled primer. Oligonucleotide primers HS34 and HS36 were used in primer extension reactions for pigA and smaI respectively.

\section{Authors' contributions}

TG drafted the manuscript, participated in design of the study and performed all experiments that are not credited to the additional authors, listed below. PF generated multiple strains (PCF\# strains) and plasmids used in the study, participated in sequencing phoBR, participated in design of the study and critically reviewed the manuscript. LE isolated strains BR1 and BR9, performed primer extension analysis, participated in sequencing phoBR and pst$S C A B-p h o U$, and participated in design of the study. NW generated strain NW201 and NW202, measured pstC::uidA expression and participated in sequencing of pstSCAB-phoU. GS conceived of the study and participated in the design and coordination of the study.

\section{Additional material}

\section{Additional file 1}

Bacterial strains, phages and plasmids used in this study. A list of strains, phage and plasmids used in this study.

Click here for file

[http://www.biomedcentral.com/content/supplementary/14712180-9-112-S1.doc]

\section{Acknowledgements}

We thank all members of the Salmond group for helpful discussions, I. Foulds for technical assistance and Corinna Richter for the identification of strain PCF58A9. This work was supported by the BBSRC, UK. TG and LE were supported by BBSRC studentships.

\section{References}

I. Wanner BL: Phosphorous assimilation and control of the phosphate regulon. In Escherichia coli and Salmonella: Cellular and Molecular Biology Volume I. Edited by: Neidhart RCI, Ingraham JL, Lin ECC, Low KB, Magasanik B, Reznikoff WS, Riley M, Schaechter M, Umbrager HE. American Society for Microbiology, Washington, DC; 1996:1357-1381.

2. Harris RM, Webb DC, Howitt SM, Cox GB: Characterization of PitA and PitB from Escherichia coli. J Bacteriol 200I, I 83(I 7):5008-50|4.

3. Rosenberg H, Gerdes RG, Chegwidden K: Two systems for the uptake of phosphate in Escherichia coli. J Bacteriol 1977, I3 I (2):505-5 I I. 
4. Rosenberg H, Gerdes RG, Harold FM: Energy coupling to the transport of inorganic phosphate in Escherichia coli KI2. Biochem J 1979, I 78(I): I33-137.

5. Amemura M, Makino K, Shinagawa H, Kobayashi A, Nakata A: Nucleotide sequence of the genes involved in phosphate transport and regulation of the phosphate regulon in Escherichia coli. J Mol Biol I 985, I 84(2):24I-250.

6. Surin BP, Rosenberg H, Cox GB: Phosphate-specific transport system of Escherichia coli: nucleotide sequence and genepolypeptide relationships. J Bacteriol 1985, I6 I (I): I89-198.

7. Webb DC, Rosenberg H, Cox GB: Mutational analysis of the Escherichia coli phosphate-specific transport system, a member of the traffic ATPase (or ABC) family of membrane transporters. A role for proline residues in transmembrane helices. J Biol Chem 1992, 267(34):2466I-24668.

8. Willsky GR, Malamy MH: Characterization of two genetically separable inorganic phosphate transport systems in Escherichia coli. J Bacteriol 1980, I44(I):356-365.

9. Yamada M, Makino K, Amemura M, Shinagawa H, Nakata A: Regulation of the phosphate regulon of Escherichia coli: analysis of mutant phoB and phoR genes causing different phenotypes. J Bacteriol I 989, I 7 I(1 0):560 I-5606.

10. Kimura S, Makino K, Shinagawa H, Amemura M, Nakata A: Regulation of the phosphate regulon of Escherichia coli: characterization of the promoter of the pstS gene. Mol Gen Genet I989, 2 I 5(3):374-380.

II. Makino K, Shinagawa H, Amemura M, Kimura S, Nakata A, Ishihama A: Regulation of the phosphate regulon of Escherichia coli. Activation of pstS transcription by $\mathrm{PhoB}$ protein in vitro. J Mol Biol 1988, 203(I):85-95

12. Makino K, Shinagawa $H$, Amemura $M$, Nakata A: Nucleotide sequence of the phoB gene, the positive regulatory gene for the phosphate regulon of Escherichia coli K-I 2. J Mol Biol I 986, I 90(I):37-44.

13. Hulett FM: The signal-transduction network for Pho regulation in Bacillus subtilis. Mol Microbiol 1996, I 9(5):933-939.

14. Sola-Landa A, Rodriguez-Garcia A, Apel AK, Martin JF: Target genes and structure of the direct repeats in the DNA-binding sequences of the response regulator PhoP in Streptomyces coelicolor. Nucleic Acids Res 2008, 36(4): I358- I 368.

15. Steed PM, Wanner BL: Use of the rep technique for allele replacement to construct mutants with deletions of the pstSCAB-phoU operon: evidence of a new role for the PhoU protein in the phosphate regulon. J Bacteriol 1993, I 75(2I):6797-6809.

16. Wang Z, Choudhary A, Ledvina PS, Quiocho FA: Fine tuning the specificity of the periplasmic phosphate transport receptor. Site-directed mutagenesis, ligand binding, and crystallographic studies. J Biol Chem 1994, 269(40):2509|-25094.

17. Martin JF, Marcos AT, Martin A, Asturias JA, Liras P: Phosphate control of antibiotic biosynthesis at the transcriptional level. Washington, DC: American Society for Microbiology; 1994.

18. Harris AK, Williamson NR, Slater H, Cox A, Abbasi S, Foulds I, Simonsen HT, Leeper FJ, Salmond GP: The Serratia gene cluster encoding biosynthesis of the red antibiotic, prodigiosin, shows species- and strain-dependent genome context variation. Microbiology 2004, I 50(Pt I I):3547-3560.

19. Williamson NR, Fineran PC, Ogawa W, Woodley LR, Salmond GP: Integrated regulation involving quorum sensing, a two-component system, a GGDEF/EAL domain protein and a posttranscriptional regulator controls swarming and RhIAdependent surfactant biosynthesis in Serratia. Environ Microbiol 2008, I0(5): 1202-1217.

20. Manderville RA: Synthesis, proton-affinity and anti-cancer properties of the prodigiosin-group natural products. Curr Med Chem Anti-Canc Agents 200I, I (2):195-218.

21. Perez-Tomas R, Montaner B, Llagostera E, Soto-Cerrato V: The prodigiosins, proapoptotic drugs with anticancer properties. Biochem Pharmacol 2003, 66(8): | 447-|452.

22. Williamson NR, Fineran PC, Gristwood T, Chawrai SR, Leeper FJ, Salmond GP: Anticancer and immunosuppressive properties of bacterial prodiginines. Future Microbiol 2007, 2:605-618.

23. Bycroft BW, Maslen C, Box SJ, Brown A, Tyler JW: The biosynthetic implications of acetate and glutamate incorporation into (3R,5R)-carbapenam-3-carboxylic acid and (5R)-car- bapen-2-em-3-carboxylic acid by Serratia sp. J Antibiot (Tokyo) 1988, 4 | (9): | 23 | - | 242

24. Parker WL, Rathnum ML, Wells JS Jr, Trejo WH, Principe PA, Sykes RB: SQ 27,860, a simple carbapenem produced by species of Serratia and Erwinia. J Antibiot (Tokyo) 1982, 35(6):653-660.

25. Thomson NR, Crow MA, McGowan SJ, Cox A, Salmond GP: Biosynthesis of carbapenem antibiotic and prodigiosin pigment in Serratia is under quorum sensing control. Mol Microbiol 2000, 36(3):539-556.

26. Williamson NR, Simonsen HT, Ahmed RA, Goldet G, Slater H, Woodley L, Leeper FJ, Salmond GP: Biosynthesis of the red antibiotic, prodigiosin, in Serratia: identification of a novel 2 methyl-3-n-amyl-pyrrole (MAP) assembly pathway, definition of the terminal condensing enzyme, and implications for undecylprodigiosin biosynthesis in Streptomyces. Mol Microbiol 2005, 56(4):971-989.

27. Williamson NR, Fineran PC, Leeper FJ, Salmond GP: The biosynthesis and regulation of bacterial prodiginines. Nat Rev Microbiol 2006, 4( I 2):887-899.

28. Fineran PC, Slater H, Everson L, Hughes K, Salmond GP: Biosynthesis of tripyrrole and beta-lactam secondary metabolites in Serratia: integration of quorum sensing with multiple new regulatory components in the control of prodigiosin and carbapenem antibiotic production. Mol Microbiol 2005, 56(6): | $495-1517$

29. Slater H, Crow M, Everson L, Salmond GP: Phosphate availability regulates biosynthesis of two antibiotics, prodigiosin and carbapenem, in Serratia via both quorum-sensing-dependent and -independent pathways. Mol Microbiol 2003, 47(2):303-320.

30. Van Houdt R, Givskov M, Michiels CW: Quorum sensing in Serratia. FEMS Microbiol Rev 2007, 3 I (4):407-424.

31. Thomson NR, Cox A, Bycroft BW, Stewart GS, Williams P, Salmond GP: The rap and hor proteins of Erwinia, Serratia and Yersinia: a novel subgroup in a growing superfamily of proteins regulating diverse physiological processes in bacterial pathogens. Mol Microbiol 1997, 26(3):531-544.

32. Cathelyn JS, Crosby SD, Lathem WW, Goldman WE, Miller VL: RovA, a global regulator of Yersinia pestis, specifically required for bubonic plague. Proc Natl Acad Sci USA 2006, 103(36): |35|4-13519.

33. Ellison DW, Lawrenz MB, Miller VL: Invasin and beyond: regulation of Yersinia virulence by RovA. Trends Microbiol 2004, I 2(6):296-300.

34. Nagel G, Lahrz A, Dersch P: Environmental control of invasin expression in Yersinia pseudotuberculosis is mediated by regulation of RovA, a transcriptional activator of the SlyA/Hor family. Mol Microbiol 200 I, 4 I (6): I249-I269.

35. Fineran PC, Williamson NR, Lilley KS, Salmond GP: Virulence and prodigiosin antibiotic biosynthesis in Serratia are regulated pleiotropically by the GGDEF/EAL domain protein, PigX. Bacteriol 2007, I 89(2I):7653-7662.

36. Gristwood T, Fineran PC, Everson L, Salmond GP: PigZ, a TetR/ AcrR family repressor, modulates secondary metabolism via the expression of a putative four-component resistance-nodulation-cell-division efflux pump, ZrpADBC, in Serratia sp. ATCC 39006. Mol Microbiol 2008, 69(2):418-435.

37. Moura RS, Martin JF, Martin A, Liras P: Substrate analysis and molecular cloning of the extracellular alkaline phosphatase of Streptomyces griseus. Microbiology 200I, I47(Pt 6): I525-I533.

38. Suziedeliene E, Suziedelis K, Garbenciute V, Normark S: The acidinducible asr gene in Escherichia coli: transcriptional control by the phoBR operon. J Bacteriol 1999, I 8 I(7):2084-2093.

39. Lamarche MG, Wanner BL, Crepin S, Harel J: The phosphate regulon and bacterial virulence: a regulatory network connecting phosphate homeostasis and pathogenesis. FEMS Microbiol Rev 2008, 32(3):461-473

40. Martin JF: Phosphate control of the biosynthesis of antibiotics and other secondary metabolites is mediated by the PhoRPhoP system: an unfinished story. J Bacteriol 2004, I 86( I6):5197-5201.

4I. Sola-Landa A, Moura RS, Martin JF: The two-component PhoRPhoP system controls both primary metabolism and secondary metabolite biosynthesis in Streptomyces lividans. Proc Natl Acad Sci USA 2003, I00(1 0):6133-6138.

42. Maplestone RA, Stone MJ, Williams DH: The evolutionary role of secondary metabolites-a review. Gene 1992, I I5(I):|5I-I57. 
43. Vining LC: Secondary metabolism, inventive evolution and biochemical diversity-a review. Gene 1992, I I5(I-2): | 35- I 40.

44. Larsen RA, Wilson MM, Guss AM, Metcalf WW: Genetic analysis of pigment biosynthesis in Xanthobacter autotrophicus Py2 using a new, highly efficient transposon mutagenesis system that is functional in a wide variety of bacteria. Arch Microbiol 2002, I78(3): | 93-20I.

45. Herrero A, Flores E: Transport of basic amino acids by the dinitrogen-fixing cyanobacterium Anabaena PCC 7I20. J Biol Chem 1990, 265(7):393 I-3935.

46. Bainton NJ, Stead P, Chhabra SR, Bycroft BW, Salmond GP, Stewart GS, Williams P: N-(3-oxohexanoyl)-L-homoserine lactone regulates carbapenem antibiotic production in Erwinia carotovora. Biochem J 1992, 288(Pt 3):997-1004.

47. de Lorenzo V, Herrero M, Jakubzik U, Timmis KN: Mini-Tn5 transposon derivatives for insertion mutagenesis, promoter probing, and chromosomal insertion of cloned DNA in gramnegative eubacteria. J Bacteriol 1990, I72(I I):6568-6572.

48. Fineran PC, Everson L, Slater H, Salmond GP: A GntR family transcriptional regulator (PigT) controls gluconate-mediated repression and defines a new, independent pathway for regulation of the tripyrrole antibiotic, prodigiosin, in Serratia. Microbiology 2005, I5 I (Pt I 2):3833-3845.

49. Lodge J, Fear J, Busby S, Gunasekaran P, Kamini NR: Broad host range plasmids carrying the Escherichia coli lactose and galactose operons. FEMS Microbiol Lett I992, 74(2-3):27I-276.

50. Sambrook J, Fritsch EF, Maniatis T: Molecular Cloning: a Laboratory Manual. 2nd edition. New York, NY: Cold Spring Harbour Laboratory Press; 1989.

5I. Altschul SF, Madden TL, Schaffer AA, Zhang J, Zhang Z, Miller W, Lipman D]: Gapped BLAST and PSI-BLAST: a new generation of protein database search programs. Nucleic Acids Res 1997, 25(I7):3389-3402.

52. Brickman E, Beckwith J: Analysis of the regulation of Escherichia coli alkaline phosphatase synthesis using deletions and phi80 transducing phages. J Mol Biol 1975, 96(2):307-316.

Publish with Bio Med Central and every scientist can read your work free of charge

"BioMed Central will be the most significant development for disseminating the results of biomedical research in our lifetime. "

Sir Paul Nurse, Cancer Research UK

Your research papers will be:

- available free of charge to the entire biomedical community

- peer reviewed and published immediately upon acceptance

- cited in PubMed and archived on PubMed Central

- yours - you keep the copyright
BioMedcentral 